\title{
Original
}

\section{Effects of Tap Water, Orange Juice and Milk on Surface Temperature and pH of Deoxygenates and Desiccants in Artificial Stomach Fluid}

\author{
Masashi SaIto $^{1)}$, Kumiko Nagayama ${ }^{2)}$, Toshinori Yamamoto ${ }^{3)}$, \\ Mitsugu TomioKA ${ }^{4)}$, Toshitaka TAKenOUCHI ${ }^{4)}$, Yoko ITO ${ }^{4)}$, \\ Atsuko Minemura ${ }^{4}$, Jun-Ichiro Murayama ${ }^{4)}$, Toru Aruga ${ }^{5)}$ \\ and Katsuji Oguchi ${ }^{6)}$
}

\begin{abstract}
We examined the effect on $\mathrm{pH}$ and temperature of deoxygenates and desiccants after the addition of artificial stomach fluid $(0.01 \mathrm{~N} \mathrm{HCl} / 0.9 \%$ $\mathrm{NaCl}$ solution), tap water, orange juice, and milk. Surface temperature was monitored with an iron-constantan thermometer with analogue-digital converter. RAYM $^{\mathbb{R}}$, which was made of calcium oxide, showed significantly increased surface temperature with addition of artificial stomach fluid, whereas the addition of orange juice significantly reduced $\mathrm{pH}$. The addition of $500 \mathrm{~mL}$ of orange juice to $3 \mathrm{~g}$ of Ageless ${ }^{(\mathrm{R})}$ demonstrated acidification of surface $\mathrm{pH}$ without increasing surface temperature. In Silica $\mathrm{Gel}^{\mathrm{R}}$, temperature was modestly increased and $\mathrm{pH}$ was elevated by milk. With respect to Ageless ${ }^{\mathbb{R}}$, we observed slight increases of temperature and $\mathrm{pH}$ rose with the addition of tap water. Our results suggest that physiological damage could be reduced by orange juice when deoxygenates and/or desiccants are ingested.
\end{abstract}

Key words : oxygen absorber, desiccants, deoxygenates, caustic agents, silica gel

\section{Introduction}

Desiccants and deoxygenates have been widely used to maintain freshness of food and drugs. However, many accidents caused by ingestion of desiccants and deoxygenates by infants and small children have been reported ${ }^{1-6)}$. Garcia Diaz et al reported that the most common type of caustic substance ingested was lye, and the stomach was the most commonly affected part of the digestive tract after lye or acid ingestion ${ }^{5)}$. When such an accident occurs, patients arrive at hospitals or clinics, and medical staff assist the patient by intubation or administration of antidotes. If it is a more urgent situation or there is a delay with the ambulance, ingestion of drinks such as milk, tap water or orange juice (a mildly acidic drink) is a recommended method to prevent severe injury of the digestive tract. In this respect, there are a few clinical reports for the treatment of patients based

\footnotetext{
") Division of Pharmacy, Showa University Fujigaoka Hospital, 1-30 Fujigaoka Aoba-ku, Yokohama 227-8501, Japan.

2) Japan Medical Systems Co. Ltd.

3) Department of Clinical Pharmacy, School of Pharmaceutical Sciences, Showa University.

4) Department of Pharmacy Services, Showa University Hospital.

5) Department of Emergency and Critical Care Medicine, Showa University, School of Medicine.

6) First Department of Pharmacology, Showa University, School of Medicine.
} 
on the chemical principle ${ }^{7.8)}$. The increase and/or decrease of temperature and $\mathrm{pH}$ of the agents are good parameters for prediction of caustic effects in the human body as they reflect convalescence ${ }^{2-6}$. The ingestion of alkaline substances causes esophageal burning and emesis may cause recurrence, consequently the high $\mathrm{pH}$ requires a neutralizing agent with no pyrogenic properties.

In this paper, we describe the effects of tap water, orange juice and milk on $\mathrm{pH}$ and temperature, by using desiccants and deoxygenates in artificial stomach fluid.

\section{Materials and Methods}

\section{Chemicals and commercial products}

The oxygen absorber, Ageless ${ }^{\mathbb{R}}$ was obtained from Mitsubishi Gas Chemical Inc. (Tokyo, Japan). Commercial forms of the desiccant calcium oxide were also obtained: RAYM ${ }^{\mathbb{R}}$ (OhE Chemicals Inc., Osaka, Japan), Kyoryoku Sekkai Kansouzai ${ }^{\circledR}$ (Kurosawa Co., Ltd. Gumma, Japan), and Neo Dryer ${ }^{\mathbb{R}}$ (Yabashi Mine Parc Co., Ltd. Gifu, Japan). Commercial forms of the desiccant silica gel were obtained: Silica Gel ${ }^{\mathbb{R}}$ (Fuji Gel Sangyo, Ltd. Osaka), Desipak $^{\circledR}$ (OhE Chemicals Inc., Osaka), and Doraiyan ${ }^{\circledR}$ (Yamani Chemical Co., Ltd. Osaka). Hydrogen chloride was purchased from Wako Pure Chemical Co., Ltd. (Tokyo). The squeezed orange juice and sterilized milk were purchased from Meiji Dairies Co. (Tokyo), and Morinaga Milk Industry Co., Ltd. (Tokyo), respectively.

\section{Apparatus and measurement of $\mathrm{pH}$ and temperature}

An iron-constantan bimetal thermometer (Osawa Co., Ltd. Tokyo) was equipped with an analogue-digital converter (Azone Co., Ltd. Tokyo, Japan). The thermometer was calibrated and corrected with a mercury thermometer. The thermometer was used to measure the temperature on the surface of the agents (Fig. 1). A pH meter Type F-21 was used (Horiba manufacturing Inc., Kyoto, Japan). Tap water, orange juice and milk were used at room temperature $\left(25^{\circ} \mathrm{C}\right)$. Artificial stomach fluid was prepared by adding $0.9 \mathrm{~g}$ of sodium chloride to $100 \mathrm{ml}$ of $0.01 \mathrm{~N} \mathrm{HCl}$ solution, and the fluid was kept at room temperature until used for the experiment. The effective temperature of drinks and the fluid was $22-23^{\circ} \mathrm{C}$ at the ambient room temperature of $25^{\circ} \mathrm{C}$.

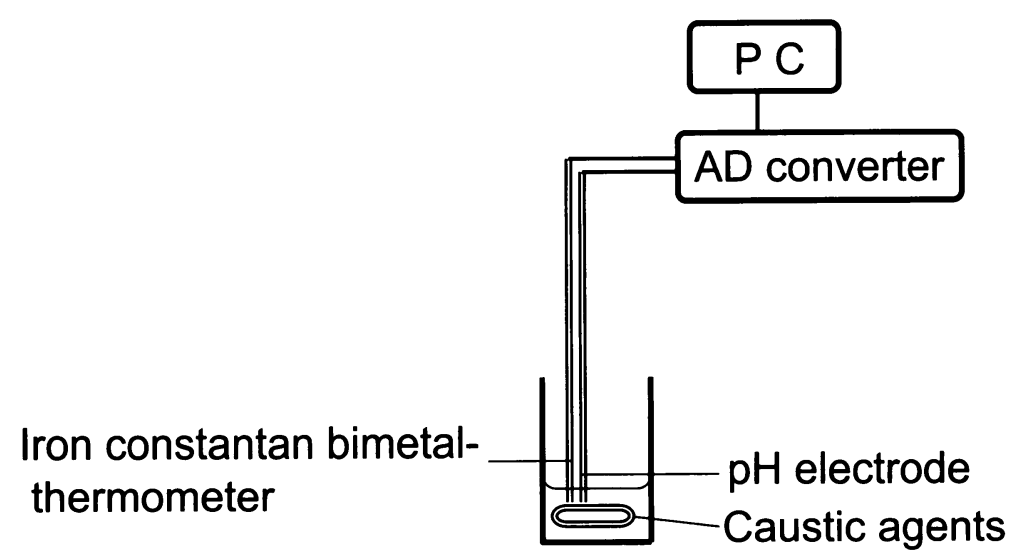

Fig. 1. Scheme of the method of $\mathrm{pH}$ and temperature measurement. 
Table 1. Summary of Chemical Properties of Oxygen Absorber, Silica Gel and Calcium Oxide on the Highest Temperature, Maximum Velocity and $\mathrm{pH}$

\begin{tabular}{|c|c|c|c|c|}
\hline Caustic Agents & Brand Name & $\begin{array}{c}\text { Highest Temperature } \\
\left({ }^{\circ} \mathrm{C}\right)\end{array}$ & $\begin{array}{l}\text { Maximum Velocity } \\
\left({ }^{\circ} \mathrm{C} / \text { second }\right)\end{array}$ & $\mathrm{pH}$ \\
\hline $\begin{array}{l}\text { Oxygen } \\
\text { Absorber }\end{array}$ & Ageless ${ }^{\mathrm{K}}$ & 36.3 & 0.8 & 7.0 \\
\hline \multirow[t]{3}{*}{ Silica Gel } & Silica Gel ${ }^{\bar{k}}$ & 35.5 & 1.7 & 2.2 \\
\hline & DESIPAK $^{\mathrm{R}}$ & 34.0 & 1.5 & 5.4 \\
\hline & DORAIYAN & 33.8 & 1.7 & 2.7 \\
\hline \multirow[t]{3}{*}{ Calcium Oxide } & RAYM ${ }^{\mathrm{R}}$ & 46.5 & 4.7 & 12.5 \\
\hline & KYORYOKU SEKKAI KANSOUZAI ${ }^{\mathrm{R}}$ & 33.5 & 0.9 & 12.6 \\
\hline & NEO DORAIYA ${ }^{\mathbb{R}}$ & 32.8 & 0.2 & 12.6 \\
\hline
\end{tabular}

\section{Experimental procedure}

1. Effect of the addition of artificial stomach fluid on the surface temperature of caustic agents. Three grams of Ageless ${ }^{\overline{\mathbb{R}}}$ or other agents as previously described were placed on the bottom of a small test tube $(3 \mathrm{~cm}$ high, $2 \mathrm{~cm}$ diameter $)$, the bimetal thermometer was placed lightly on, or the tip inserted into the agent. Temperature was measured for 6 minutes, then $0.5 \mathrm{ml}$ of artificial stomach fluid was added to the agent, and the surface temperature recorded.

2. Effect of tap water, orange juice and milk on surface $\mathrm{pH}$ in agents $\mathrm{RAYM}^{\mathrm{R}}$, Silica $\mathrm{Gel}^{\left({ }^{\mathrm{R}}\right)}$, and Ageless ${ }^{\mathrm{R}}$.

The neutralizing activity of drinks on $\mathrm{pH}$ was measured as follows; $3 \mathrm{~g}$ of the caustic agent was placed in a $500 \mathrm{ml}$ beaker, $0.5 \mathrm{ml}$ of artificial stomach fluid was added to the surface of the agent. $\mathrm{pH}$ was measured at the beginning and after each stepwise addition of $50 \mathrm{ml}$ of each drink, with total doses ranging from $0 \mathrm{ml}$ to $500 \mathrm{ml}$. The experiments were repeated at least three times to confirm the results, and typical results are shown in figs, 1-4 and Table 1.

\section{Results and Discussion}

There are several reports concerning the treatment of caustic injury by desiccants and deoxygenates ${ }^{1-8)}$, which are contained in many commercial products. Surface temperature and $\mathrm{pH}$ were monitored in vitro, as these two parameters are important in digestive tract injury. Drinks such as tap water, milk, or orange juice may be important in reducing severity of injury.

Effect of artificial stomach fluid on the surface temperature of deoxygenate and desiccant agents

The potential effects of artificial stomach fluid on surface temperature of deoxygenates and desiccants were examined (Fig. 2). After the addition of artificial stomach fluid to Ageless ${ }^{\mathbb{R}}$, temperature decreased from $36{ }^{\circ} \mathrm{C}$ to $34{ }^{\circ} \mathrm{C}$. However, there was no significant decrease of temperature for the other agents (data not shown). The results suggest that deoxygenates may be less damaging to the digestive tract, and that Ageless ${ }^{\mathrm{R}}$ may have 


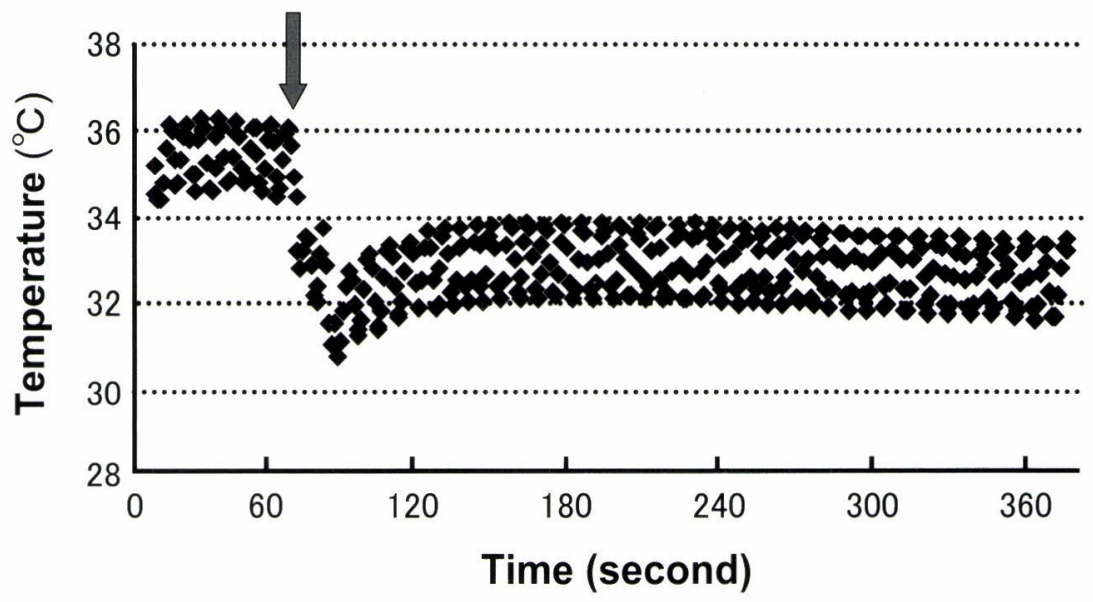

Fig. 2. Effect of the addition of artificial stomach fluid on the surface temperature of Ageless ${ }^{\mathbb{R}}$. Arrow indicates the point of adding artificial stomach fluid. The experimental conditions and details are described in Materials and Methods.

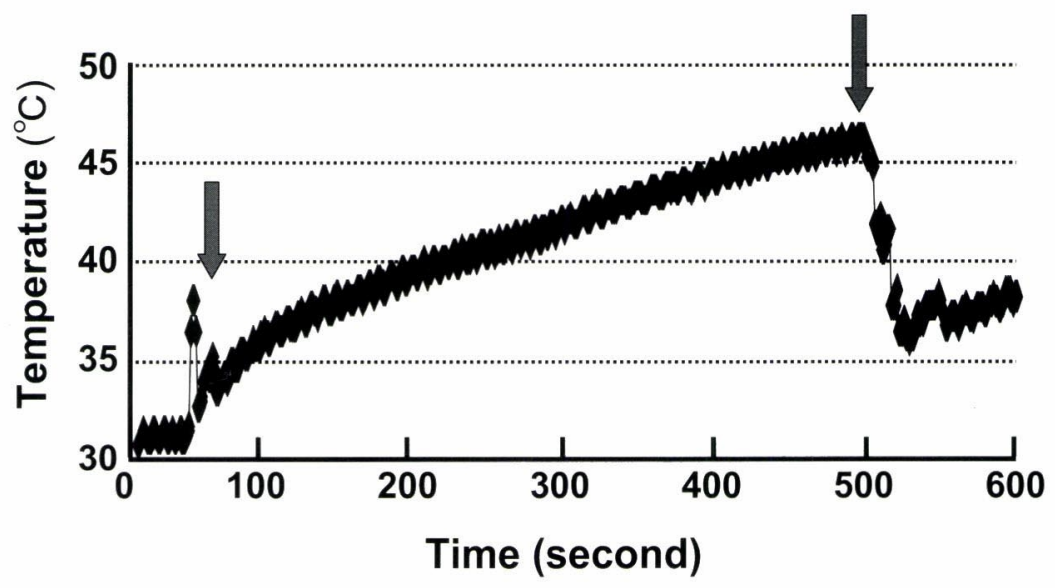

Fig. 3. Effect of artificial stomach fluid on the surface temperature of RAYM ${ }^{\circledR}$. Red arrow indicates the addition of artificial stomach fluid. Blue arrow indicates the addition of tap water. The experimental conditions and details are described in Materials and Methods.

lower risks even if a large amount was ingested. In vivo study with animals may be helpful to confirm our results.

Calcium oxide can generate heat with the addition of hydrogen chloride as follows :

$$
\begin{array}{ll}
\text { Eq.1 } & \mathrm{CaO}+\mathrm{H}_{2} \mathrm{O} \rightarrow \mathrm{Ca}(\mathrm{OH})_{2}+\mathrm{Q}(\mathrm{kJ}) \\
\text { Eq.2 } & \mathrm{Ca}(\mathrm{OH})_{2}+\mathrm{HCl}=\mathrm{CaCl}_{2}+\mathrm{H}_{2} \mathrm{O}
\end{array}
$$

As shown in Eq.1 this chemical reaction is exoergic. Temperature experiments using RAYM $^{\circledR}$ as the test agent were subsequently performed (Fig. 3). As expected, after the addition of artificial stomach fluid, temperature in the reaction mixture gradually increased in a time-dependent manner up to $46.5^{\circ} \mathrm{C}$ (Table 1). The velocity of temperature increase was $4.7^{\circ} \mathrm{C} \mathrm{s}^{-1}$, the highest among the test agents (Table 1). However, temperature was 

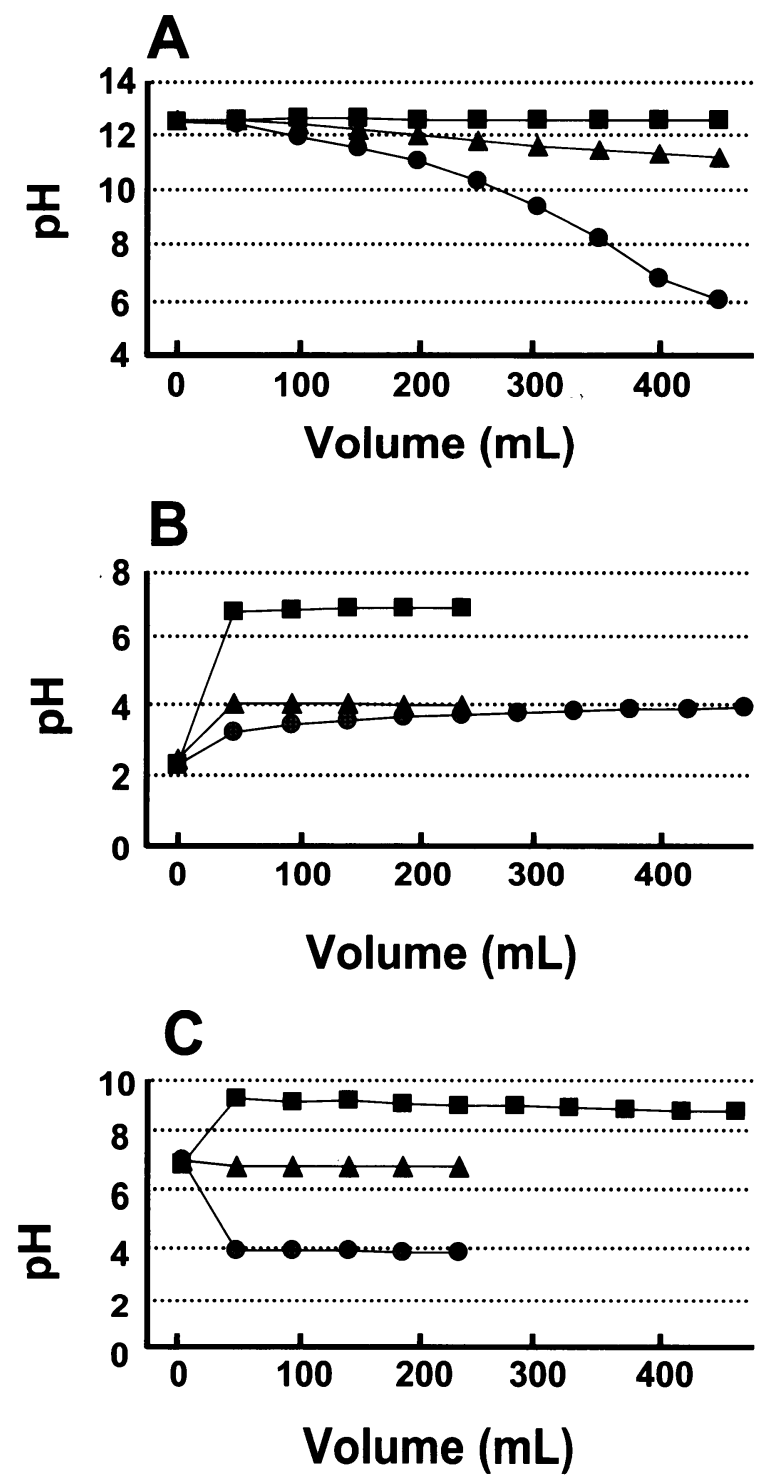

Fig. 4. Effect of tap water, orange juice and milk on surface $\mathrm{pH}$ in $\mathrm{RAYM}^{\overline{\mathrm{B}}}$ (A), Silica $\mathrm{Gel}^{\overline{\mathrm{R}}}$ (B) and Ageless $^{\mathbb{R}}(C)$. Symbols denote tap water $(\boldsymbol{\square})$, orange juice $(\boldsymbol{O})$, and milk $(\boldsymbol{\Delta})$. The experimental conditions and details are described in Materials and Methods.

reduced to approximately $36^{\circ} \mathrm{C}$ by adding tap water.

Ingestion of caustic agents often results in gastro-esophageal tract injury (so-called chemical burning $)^{1,8)}$. Such burning is thought to be caused by chemical reaction increasing the local temperature, resulting in erosion of the esophageal tract and gastric mucosa. Temperature decreased with addition of water (Fig. 3), suggesting that this could prevent some chemical burning of the gastro-esophageal tract. Therefore, we speculate that approximately $500 \mathrm{ml}$ 
of tap water for every $3 \mathrm{~g}$ of caustic agent containing $\mathrm{CaO}$ as the ingredient should significantly reduce the maximum temperature.

\section{Effect of tap water, orange juice and milk on $\mathrm{pH}$ in deoxygenates and desiccants}

The effect on $\mathrm{pH}$ of $\mathrm{RAYM}{ }^{\mathbb{R}}$, Silica $\mathrm{Gel}^{\mathbb{R}}$, and Ageless ${ }^{\mathbb{R}}$ in this in vitro system was investigated by the addition of tap water, milk or orange juice. The additional volume of these fluids in the reaction mixture ranged from $0 \mathrm{ml}$ to $500 \mathrm{ml}$. The results are shown in Fig. 4. For $\mathrm{RAYM}^{\overline{\mathrm{R}}}$ the addition of orange juice reduced $\mathrm{pH}$ from 12.5 to 6.1 in a dosedependent manner (Fig. 4A). However, tap water and milk did not significantly alter $\mathrm{pH}$, even with large additions. Testing of Silica $\mathrm{Gel}^{\circledR}$ showed a significant change from acidic to neutral conditions ( $\mathrm{pH} 2.1$ to 6.5 ) with the addition of $50 \mathrm{ml}$ milk; however, tap water and orange juice only slightly changed pH (Fig. 4B). The testing of Ageless ${ }^{\circledR}$ showed a maintained neutral $\mathrm{pH} 7.2$ with the addition of milk, whereas orange juice acidified the mixture to $\mathrm{pH} 4.0$, and tap water resulted in basic conditions of $\mathrm{pH}$ 9.0. RAYM ${ }^{\mathbb{R}}$, Kyoryoku Sekkaikansouzai ${ }^{\mathbb{R}}$ and Neo Dryer ${ }^{\circledR}$ had similar $\mathrm{pH}$ results, but with different maximum velocities of surface temperature (Table 1 ).

Because $\mathrm{pH}$ is predictive of injury, and administering milk and tap water is widely recommended as a diluent ${ }^{10-14)}$, the results suggest that raising of $\mathrm{pH}$ by ingestion of RAYM ${ }^{\circledR}$, Kyoryoku Sekkaikansouzai ${ }^{\mathbb{R}}$ and Neo Dryer ${ }^{(\mathbb{R})}$ are important risks.

Although some drinks are easily available and currently recommended for primary treatment after ingestion of desiccants and/or deoxygenates ${ }^{10-14)}$ and we conclude that physiological damage could be reduced by the administration of orange juice, the results suggest that medical staff should determine which materials have been ingested before commencing treatment.

\section{References}

1) Afzal NA, Albert D, Thomas AL and Thomson M: A child with oesophageal strictures. Lancet $359: 1032$ (2002)

2) Schier JG, Hoffman RS and Nelson LS : Desiccant-induced gastrointestinal burns in a child. Vet Hum Toxicol $44: 343-344(2002)$

3) Lamireau T, Reboujssoux L, Denis D, Lancelin F, Vergnes $P$ and Fayon $M$ : Accidental caustic ingestion in children : is endoscopy always mandatory? J Pediatr Gastroenterol Nutr 33:81-84 (2001)

4) Naon H, Shaul D, Mahnovski V and Thomas D: Fibroproliferative disorder of the antrum after an alkali ingestion. Am J Gastroenterol 91 : 383-384 (1996)

5) Garcia Diaz E, Castro Fernandez M, Romero Gomez $M$ and Castilla Higuero L: Upper gastrointestinal tract injury caused by ingestion of caustic substances. Gastroenterol Hepatol 24:191-195 (2001) (in Spanish)

6) Humberston CL, Dean BS and Krenzelok EP: Ingestion of $35 \%$ hydrogen peroxide. J Toxicol Clin Toxicol $28: 95-100(1990)$

7) Zarkovic S, Busic I and Volic A : Acute states in poisoning with corrosive substances. Med Arh 51(1-2 Suppl 1) : 43-46 (1997) (in Croacian)

8) Iacomino E, Junquera LM, Vendettuoli M, Gonzalez AM, Olay S and Corbacelli A : Distraction of oral scars contractures following caustic ingestion. A form of conservative treatment. Med Oral 8:61-65 (2003)

9) Baskerville JR, Nelson RE, Reynolds TL and Cohen M: Development of a standardized animal model for the study of alkali ingestion. Vet Hum Toxicol 44:45-47 (2002)

10) Seki S: Domestic miscellaneous goods; Sillica gel, Calcium Oxide (quick-lime), Calcium chloride, deorygenatos Primary Care of Acute Poising, Kanehara \& Co, Tokyo, pp32-36 (2002) (in Japanese)

11) Ukai S: Domestic Chemicals and dsiccants: Manual of Treatment for Acute Poisoning, Japan Poison Information Centar (Ed), 3rd ed, Yakugyo Jiho, Tokyo, pp162-172 (1999) (in Japanese)

12) Takano H: Dissection Physiology, Nanzando Publishing Co, Tokyo (2002) (in Japanese)

13) Wilson KJW and Waugh A (Ichikawa S, et al. Tr.) : Ross and Wilson Anatomy and Physiology in Health 
and Illness, Nishimura Co, Niigata (2000) (in Japanese)

14) Nakano S, Yoshioka $T$ and Tanaka E: Illustrated Physiology, Nakano S (Ed), 2nd ed, Igaku-Shoin, Tokyo (2000) (in Japanese)

[Received January 5, 2007 : Accepted January 22, 2007] 